Journal of Animal and Veterinary Advances 11 (10): 1734-1738, 2012

ISSN: $1680-5593$

(C) Medwell Journals, 2012

\title{
Genetic Parameters of Some Morphological Traits in Honey Bee Populations (Apis mellifera L.) along the Southeast Border of Turkey
}

\author{
${ }^{1}$ Gonca Ozmen Ozbakir, ${ }^{1}$ Seyrani Koncagul, ${ }^{1}$ Sahin Cadirci and ${ }^{2}$ Cetin Firatli \\ ${ }^{1}$ Department of Animal Science, Faculty of Agriculture, University of Harran, Sanliurfa, Turkey \\ ${ }^{2}$ Department of Animal Science, Faculty of Agriculture, University of Ankara, Ankara, Turkey
}

\begin{abstract}
In this study, 38 apiaries along the Southeast border of Turkey with 3 countries were visited and 3340 worker honey bee specimen were collected from 167 colonies. The worker honey bees were collected from populations in Van, Hakkari, Sirnak, Mardin, Sanliurfa, Kilis and Hatay in Turkey; Lattakia, Idlib, Aleppo, ArRaqqah and Dayr az-Zawr in Syria; Urmia, Maku and Khoy in Iran, locations along the common border in the Southeast of Turkey. Nine morphological characters measured for each worker bee were: Tongue Length (TL), length of hairs on tergite 5 (HL), Forewing Length (FWL), Forewing Width (FWW), Hind Leg Length (HLL), Cubital Index (CI), longitudinal (T3+T4), Tomentum Index (TI) and Metatarsal Index (MTI). In general, heritability estimates from pooled data ranged from $0.36 \pm 0.004$ for CI to $0.87 \pm 0.003$ for FWL from $0.42 \pm 0.004$ for CI to $0.99 \pm 0.003$ for FWL and from $0.43 \pm 0.004$ for $\mathrm{Cl}$ to $1.03 \pm 0.003$ for FWL when effective number of matings that a virgin queen made changed from 7,13 or 17 , respectively.
\end{abstract}

Key words: Honey bee, morphometry, morphological traits, genetic correlations, heritability

\section{INTRODUCTION}

Morphological characteristics of honey bee workers have been important traits for breeding systems and useful traits discriminating for subspecies and ecotypes. Also, this phenotypic characters are easily measured. Many of the characters of honey bees with economic importance are quantative and usually involve many genes, each contributing small effect. Heritability $\left(\mathrm{h}^{2}\right)$, one of the most important properties of a quantative traits, represents the ratio of the additive genetic variance to total or phenotypic variance (Collins, 1986).

Methods estimating the heritability of some characters for honey bees have been discussed by Rinderer (1977), Oldroyd and Moran (1983) and Moritz and Klepsch (1985). Honey bees are haplo-diploid organisms living in colonial aggregations and they have been showed cast and sex differences. Haplo-Diploid System changes the relatedness of relatives in the colony. Under the natural conditions, the relatedness ranges from $0.75-0.25$ for workers in the same colony depending on the number of drones mated with the queen. When the queen has been mated with many drones from the same dronemother, the relatedness between two workers can be either 0.75 or 0.50 (Collins, 1986). Virgin queens mate with several drones while flying at drone-congregating areas and generally with 7-17 drones during the mating flights
(Adams et al., 1977; Winston, 1987). Because of the polyandry in the honey bees (Apis mellifera), there are 6-21 subfamilies among the workers in a colony. By using microsatellites, 7-20 subfamilies were identified in three different subspecies (A.m. mellifera, A.m. carnica and A.m. ligustica) and A. mellifera queens mate with approximately 14 drones (Page and Metcalf, 1982; Estoup et al., 1994).

Some morphological characteristics of worker bees show correlations to production traits of colonies. There are significant and positive correlations between honey production with fore wing and hind wing measures (Szabo and Lefkovitch, 1988). The heritability of hamuli number of workers was $0.68 \pm 0.18$, estimated by sibanalysis (Oldroyd and Moran, 1983). In another study, morhological characteristics of worker bees were investigated into 2 groups: the first group included hind leg and wing sizes while the second included hairs and index characteristics. The characteristics in the first group showed more expressed phenotypic and genetic correlation than the characteristics in the second group. All heritability estimates were found large and significant (Poklukar and Kezic, 1994). Heritabilities of some morphological characters were estimated for TL, 0.64; TiL, 0.45; FeL, 0.50; MetL, 0.47; MetW, 0.33; FWL, 0.42; FWW, 0.89; HWL, 0.94 and number of hamuli, 0.45 (Mostajeran et al., 2002). Significant correlations were

Corresponding Author: Gonca Ozmen Ozbakir, Department of Animal Science, Faculty of Agriculture, University of Harran, Sanliurfa, Turkey 
found between honey yield and cubital-b index, tibia length and forewing width (Edriss et al., 2002). The traits glossal length and pupal weight presented the lowest correlation to honey production: 0.225 and 0.410 , respectively. The highest correlations were observed between length of the tibia, corbicular area and honey production: 0.587 and 0.549 , respectively. In all cases, except pupal weight, correlation was significant. These findings support that worker bees with larger corbicular areas may have a better ability to carry larger quantities of pollen to their hives and it is possible to improve honey production through, indirect selection based on this trait (Souza et al., 2002). Workers with larger corbiculae carry larger pollen loads to colony (Milne et al., 1986).

The main aim of this study was to estimate heritabilities of 9 morphological characters and the genetic correlations among them for worker honey bees sampled from natural populations without controlled matings.

\section{MATERIALS AND METHODS}

Data: In this study, the raw data collected for a Ph.D. study completed by Ozbakir were reorganized and standardized in order to obtain the estimates of the genetic parameters. In this aspect, the whole description of the data collection can be seen in the study of Ozbakir.

Briefly, the worker honey bees were collected from populations of Van, Hakkari, Sirnak, Mardin, Sanliurfa, Kilis and Hatay in Turkey; Lattakia, Idlib, Aleppo, ArRaqqah and Dayr az-Zawr in Syria; Urmia, Maku and Khoy in Iran which are located along the common border in the Southeast region of Turkey. In the Summer of 2008, 38 apiaries along the border in 3 countries were visited and 3340 worker honey bee specimen were collected from 167 colonies. Sampling localities were chosen from stationary beekeeping areas where queen replacement has not been practiced.

Young worker bees were collected from the brood areas, killed with chloroform and fixed in $70 \%$ ethanol until morphological measurements were carried out. Twenty worker honey bees were selected randomly from each sample and dissected for measurements. Nine morphological characters measured for each worker bee were: Tongue Length (TL), length of Hairs on Tergite 5 (HL), Forewing Length (FWL), Forewing Width (FWW), Hind Leg Length (HLL), Cubital Index (CI), longitudinal (T3+T4), Tomentum Index (TI) and Metatarsal Index (MTI). Body parts (tongue, right forewing and right hind leg) were mounted on projector slides and the morphological characters were measured with Leica Z16APO macroscope in accordance with the previous studies (Alpatov, 1929; Goetze, 1940; Ruttner et al., 1978).
Method of analysis: In order to obtain the estimates of heritabilities and genetic correlations, the half-sib analysis was applied to the data using SAS (2000) statistical package program. Before the analysis, the data were adjusted for the fixed effects of country city village factors due to the reason that the preliminary analyses showed that the effects of city, county and village were important couses of differences among the traits in the data.

After the variance component were obtained based on half-sib analysis in PROC VARCOMP procedure in SAS, the estimates of heritabilities were calculated using the method described in previous studies (Oldroyd and Moran, 1983; Poklukar and Kezic, 1994; Falconer and Mackay, 1996) by the equation:

$$
h^{2}=\frac{t}{r}
$$

Where:

$\mathrm{t}=$ Intraclass correlation

$r=$ The expected genetic relationship among the worker honey bees in a colony. $\mathrm{r}$ is calculated by the following model (Laidlaw and Page, 1984):

$$
\mathrm{r}=\frac{1}{2}\left(\frac{1}{2}+\frac{1}{\mathrm{~m}}\right)
$$

where, $m$ is the number of drones mated with the queen. The assumption was the Case 2 described by Oldroyd and Moran (1983) that a virgin queen was mated with $\mathrm{m}$ unrelated drones and each drones contributed to next generation with equal amount of sperm. Upward bias in heritability estimates was calculated and removed from the heritability estimates and the approximate standard errors of the heritabilities were calculated by the equations shown by Oldroyd and Moran (1983).

In general, it is assumed that a virgin queen mates with 7,13 or 17 drones in uncontrolled mating environment (Adams et al., 1977; Oldroyd and Moran, 1983; Winston, 1987). Thus, in this study, researchers calculated three different $r$ values assuming the virgin queen mated with 7,13 or 17 drones at the time of mating in order to show the range of heritability estimates as if a queen would have mated with the minimum, modarate or the maximum number of drones. The estimates of genetic correlations were calculated by half-sib covariance analysis described by Duzgunes.

\section{RESULTS}

Heritabilities of some morphological characters of honey bees from Turkey, Syria and Iran is shown in Table 1. When it is supposed that a Virgin Queen Mated 
with 7,13 or 17 drones, the estimated heritabilities progresively increased due to the reason that the coefficient (r) of expected genetic relationship among a colony members decreased. Consequently, the number of drones mated with a queen is getting larger the intraclass correlation, calculated from variance components obtained from sib-analysis is devided by smaller quantity and yields higher value of the parameter.

Heritabilities of morphological characters of worker bees from Turkey group were higher for TL, FWW, CI, $\mathrm{T} 3+\mathrm{T} 4$ and TI characters than those obtained in Syria and
Iran. The highest estimates of heritability were obtained for FWL, HLL and MTI characters in Syria and for HL in Iran. The smallest estimates of heritability for HL was obtained in Turkey for CI in Syria and for all the other characters in this study in Iran. In general from the analysis of the data pooled across Turkey, Syria and Iran, the highest estimate of heritability was obtained for the character FWL followed by TL, FWW, HLL, TI, HL, T3+T4, MTI and CI, respectively (Table 1).

Genetic correlations among morphological characters of worker honey bees are shown in Table 2 . The genetic correlations between TL withFWL (0.693) and HLL (0.602)

Table 1: Heritabilities and standard errors of morphol ogical characters of honey bees from Turkey, Syria and Iran, based on sib analysis

\begin{tabular}{|c|c|c|c|c|c|c|c|c|c|c|c|c|}
\hline \multirow{3}{*}{$\begin{array}{l}\text { Effective } \\
\text { number } \\
\text { of mating }\end{array}$} & \multicolumn{12}{|l|}{ Country } \\
\hline & \multicolumn{6}{|l|}{ Turkey } & \multicolumn{3}{|l|}{ Iran } & \multicolumn{3}{|l|}{ Pooled } \\
\hline & 7 & 13 & 17 & 7 & 13 & 17 & 7 & 13 & 17 & 7 & 13 & 17 \\
\hline $\mathrm{TL}$ & $0.89 \pm 0.003$ & $1.02 \pm 0.004$ & $1.06 \pm 0.003$ & $0.67 \pm 0.006$ & $0.77 \pm 0.007$ & $0.80 \pm 0.007$ & $0.34 \pm 0.010$ & $0.39 \pm 0.011$ & $0.40 \pm 0.012$ & $0.79 \pm 0.003$ & $0.90 \pm 0.003$ & $0.94 \pm 0.003$ \\
\hline $\mathrm{HL}$ & $0.70 \pm 0.004$ & $0.80 \pm 0.004$ & $0.83 \pm 0.004$ & $0.76 \pm 0.006$ & $0.87 \pm 0.006$ & $0.90 \pm 0.007$ & $0.77 \pm 0.008$ & $0.88 \pm 0.009$ & $0.91 \pm 0.009$ & $0.71 \pm 0.002$ & $0.82 \pm 0.003$ & $0.85 \pm 0.003$ \\
\hline FWL & $0.92 \pm 0.003$ & $1.05 \pm 0.004$ & $1.09 \pm 0.004$ & $0.94 \pm 0.006$ & $1.07 \pm 0.007$ & $1.11 \pm 0.007$ & $0.24 \pm 0.011$ & $0.27 \pm 0.012$ & $0.28 \pm 0.012$ & $0.87 \pm 0.003$ & $0.99 \pm 0.003$ & $1.03 \pm 0.003$ \\
\hline FWW & $0.86 \pm 0.003$ & $0.99 \pm 0.004$ & $1.03 \pm 0.004$ & $0.71 \pm 0.006$ & $0.81 \pm 0.007$ & $0.84 \pm 0.007$ & $0.56 \pm 0.009$ & $0.64 \pm 0.010$ & $0.67 \pm 0.010$ & $0.79 \pm 0.003$ & $0.91 \pm 0.003$ & $0.94 \pm 0.003$ \\
\hline HLL & $0.80 \pm 0.004$ & $0.91 \pm 0.004$ & $0.95 \pm 0.004$ & $0.89 \pm 0.006$ & $1.02 \pm 0.007$ & $1.06 \pm 0.007$ & $0.44 \pm 0.010$ & $0.50 \pm 0.011$ & $0.52 \pm 0.012$ & $0.78 \pm 0.003$ & $0.89 \pm 0.003$ & $0.93 \pm 0.003$ \\
\hline CI & $0.45 \pm 0.005$ & $0.51 \pm 0.005$ & $0.53 \pm 0.006$ & $0.19 \pm 0.009$ & $0.21 \pm 0.010$ & $0.22 \pm 0.010$ & $0.22 \pm 0.015$ & $0.25 \pm 0.017$ & $0.26 \pm 0.017$ & $0.36 \pm 0.004$ & $0.42 \pm 0.004$ & $0.43 \pm 0.004$ \\
\hline $\mathrm{T} 3+\mathrm{T} 4$ & $0.64 \pm 0.004$ & $0.73 \pm 0.004$ & $0.76 \pm 0.004$ & $0.54 \pm 0.007$ & $0.61 \pm 0.007$ & $0.64 \pm 0.008$ & $0.46 \pm 0.001$ & $0.51 \pm 0.011$ & $0.53 \pm 0.008$ & $0.58 \pm 0.003$ & $0.67 \pm 0.003$ & $0.70 \pm 0.004$ \\
\hline $\mathrm{TI}$ & $0.86 \pm 0.007$ & $0.98 \pm 0.008$ & $1.02 \pm 0.008$ & $0.50 \pm 0.010$ & $0.56 \pm 0.012$ & $0.58 \pm 0.012$ & $0.16 \pm 0.012$ & $0.18 \pm 0.014$ & $0.19 \pm 0.014$ & $0.76 \pm 0.004$ & $0.87 \pm 0.005$ & $0.90 \pm 0.005$ \\
\hline MTI & $0.58 \pm 0.084$ & $0.66 \pm 0.093$ & $0.69 \pm 0.097$ & $0.62 \pm 0.214$ & $0.71 \pm 0.240$ & $0.74 \pm 0.247$ & $0.46 \pm 0.373$ & $0.52 \pm 0.420$ & $0.54 \pm 0.430$ & $0.57 \pm 0.052$ & $0.65 \pm 0.060$ & $0.67 \pm 0.060$ \\
\hline \multicolumn{13}{|c|}{$\begin{array}{l}\text { Tongue Length (TL), Length of Hairs on Tergite } 5 \text { (HL), Forewing Length (FWL), Forewing Width (FWW), Hindleg Length (HLL), Cubital Index (CT), Longitudinal } \\
\text { (T3+T4), Tomentum index (TI) and Metatarsal Index (MTI) }\end{array}$} \\
\hline \multirow{2}{*}{$\begin{array}{l}\text { Table 2: Ge } \\
\text { Variables }\end{array}$} & \multirow{2}{*}{\multicolumn{2}{|c|}{ Location }} & IT & \multirow{2}{*}{\multicolumn{2}{|c|}{ FWL }} & & IT T & \multirow{2}{*}{\multicolumn{2}{|c|}{$\mathrm{CI}$}} & & & \\
\hline & & & $\mathrm{HL}$ & & & FWW & HLL & & & $\mathrm{T} 3+\mathrm{T} 4$ & TI & MTI \\
\hline \multirow[t]{4}{*}{$\mathrm{TL}$} & \multicolumn{2}{|l|}{$\mathrm{L} 1$} & 0.122 & \multicolumn{2}{|l|}{0.693} & 0.531 & 0.602 & \multicolumn{2}{|c|}{-0.252} & 0.471 & -0.254 & -0.039 \\
\hline & $\mathrm{L} 2$ & & 0.172 & \multicolumn{2}{|l|}{0.703} & 0.509 & 0.685 & \multicolumn{2}{|c|}{0.554} & 0.618 & -0.524 & -0.371 \\
\hline & L3 & & -0.414 & \multicolumn{2}{|l|}{0.285} & 0.488 & 0.482 & \multicolumn{2}{|c|}{-0.162} & -0.245 & -0.025 & -0.281 \\
\hline & Pool ed & & 0.154 & \multicolumn{2}{|l|}{0.710} & 0.550 & 0.592 & -0.21 & & 0.490 & -0.222 & 0.070 \\
\hline $\mathrm{HL}$ & $\mathrm{L} 1$ & & & 0.171 & & 0.019 & 0.023 & -0.02 & & 0.085 & 0.069 & 0.064 \\
\hline & L2 & & & 0.169 & & 0.332 & 0.067 & -0.05 & & -0.019 & -0.427 & -0.187 \\
\hline & L3 & & & 0.227 & & -0.028 & -0.656 & 0.71 & & 0.513 & 0.481 & 0.027 \\
\hline & Pooled & & & 0.169 & & -0.065 & 0.076 & -0.09 & & 0.064 & 0.155 & 0.152 \\
\hline FWL & $\mathrm{L} 1$ & & & & & 0.744 & 0.737 & -0.26 & & 0.536 & -0.364 & -0.098 \\
\hline & $\mathrm{L} 2$ & & & & & 0.719 & 0.834 & -0.29 & & 0.503 & -0.487 & -0.269 \\
\hline & L3 & & & & & 0.635 & -0.302 & -0.29 & & 0.002 & -0.463 & 0.316 \\
\hline & Pooled & & & & & 0.776 & 0.750 & -0.27 & & 0.585 & -0.353 & -0.065 \\
\hline FWW & $\mathrm{L} 1$ & & & & & & 0.583 & -0.02 & & 0.350 & -0.279 & -0.042 \\
\hline & $\mathrm{L} 2$ & & & & & & 0.533 & -0.42 & & 0.161 & -0.300 & -0.205 \\
\hline & L3 & & & & & & 0.279 & -0.19 & & -0.330 & 0.177 & 0.246 \\
\hline & Pooled & & & & & & 0.638 & 0.05 & & 0.486 & -0.302 & -0.027 \\
\hline HLL & L1 & & & & & & & -0.16 & & 0.421 & -0.285 & -0.276 \\
\hline & $\mathrm{L} 2$ & & & & & & & -0.43 & & 0.436 & -0.480 & -0.415 \\
\hline & L3 & & & & & & & -0.54 & & -0.647 & 0.233 & -0.271 \\
\hline & Pooled & & & & & & & -0.08 & & 0.519 & -0.277 & -0.228 \\
\hline $\mathrm{CI}$ & $\mathrm{L} 1$ & & & & & & & & & -0.021 & -0.022 & 0.125 \\
\hline & L2 & & & & & & & & & 0.105 & 0.115 & 0.369 \\
\hline & L3 & & & & & & & & & 0.735 & 0.572 & 0.023 \\
\hline & Pooled & & & & & & & & & -0.123 & -0.058 & 0.087 \\
\hline $\mathrm{T} 3+\mathrm{T} 4$ & $\mathrm{~L} 1$ & & & & & & & & & & -0.272 & 0.024 \\
\hline & L2 & & & & & & & & & & -0.395 & -0.044 \\
\hline & $\mathrm{R} 3$ & & & & & & & & & & -0.133 & 0.394 \\
\hline & Pooled & & & & & & & & & & -0.270 & 0.004 \\
\hline TI & L1 & & & & & & & & & & & 0.102 \\
\hline & L2 & & & & & & & & & & & 0.329 \\
\hline & L3 & & & & & & & & & & & 0.253 \\
\hline & Pooled & & & & & & & & & & & 0.055 \\
\hline
\end{tabular}

L1: Turkey, L2: Syria, L3: Iran, Pool ed: All data combined; Tongue Length (TL), length of hairs on tergite 5 (HL), Forewing Length (FWL), Forewing Width (FWW), Hindleg Length (HLL), Cubital Index (CT), Longitudinal (T3+T4), Tomentum Index (TI) and Metatarsal Index (MTI) 
are found relatively high in honey bees from Southeast border of Turkey. Positive genetic correlation between FWW and HLL is found high in Turkey and Syria groups, 0.737 and 0.834 , respectively. High positive genetic correlations is expected between FWL and FWW and negative correlations is expected between wing sizes and CI. Genetic correlations of morphological characters of honey bees from Iran group are found relatively low. Only genetic correlations among $\mathrm{CI}$ with $\mathrm{HL}(0.712)$ and $\mathrm{T} 3+\mathrm{T} 4$ $(0.735)$ are found high in Iran group. Negative genetic correlations are found between TL with TI, FWL with CI and TI, HLL with CI and MTI and T3+T4 and TI in all groups.

\section{DISCUSSION}

The estimates of heritabilities of the characters (except CI) considered in this study were higher in Turkey and more similar to those in Syria group than those in Iran group. Especially, the heritability of forewing sizes were found high and similar in Turkey and Syria groups. All the estimates of heritabilities of morphometric characters of worker bees were found low in Iran group except for $\mathrm{HL}$. Low genetic variation among worker honey bee samples and sample size might be effective on this result in Iran group. Moreover, it might be the result of geographical condititons in which the worker honey bees sampled in Iran from where it is almost impossible for honey bee colonies move into or out, thus in such a region, there is a high possibility of some degree of inbereeding that causes a decrease in genetic variability.

The Cubital Index (CI) and the length of hair on tergite 5 (HL) are useful morphological traits in discriminating European races (Ruttner, 1988). In this study, the estimates of heritability of $\mathrm{HL}$ were found high for each groups and the all data pooled over the regions. When queens mate 17 drone, pooled heritability of $\mathrm{HL}$ and CI were found 0.85 and 0.43 , respectively.

Oldroyd and Moran (1983)'s Method give examination chance for the genetic parameters in natural populations. The results in this study showed that morphological characters of worker honey bees are highly heritable. Previous findings have supported that there are correlations between some morphometric characters and production traits. Especially, forewing and hindleg sizes are highly correlated with honey production (Milne et al., 1986; Szabo and Lefkovitch, 1988; Souza et al., 2002; Mostajeran et al., 2006). Morphometry used for classification of honey bee subspecies and ecotypes is also easy tool for determining honey bee stock purity. To design selection and breeding program for honey bee populations with natural and unknown production traits, morphology of workers may be clue in the first stage. Knowing heritabilities of morphological characters of workers from free mated queens may give important information useful in an indirect selection program.

It is obviously expected that the intracolonial conditions increase the similarity among the individuals in the same colony and results in increase in genotypic and phenotypic differences with the other colonies (Bulmer, 1985). The maternal effect and the environmental conditions and also queen-drones genotype cause morphological differentiation between the worker bees in different colonies. In this study, sampling area was wide and the border between three countries has different geographical conditions possibly causing a formation of different honey bee subspecies.

Previous study showed that morphological characters of honey bees from southeast border of Turkey have more similarity to Syrian honeybees than to Iranian honeybees although, Syrian and Iranian honey bee samples were clustered separately. Mahalanobis distances also showed that Syrian and Iranian honey bee group centroids were distant whereas the honey bees in the southeast region of Turkey were closer to Syrian than Iranian.

\section{CONCLUSION}

The results of this study shows that the heritabilities of morphological characters of worker bees from Turkey and Syria have more similarities and higher than those in Iran. Thus, the high heritabilities and the genetic correlations between forewing sizes and hindleg length of worker honey bees should be taken in to account in an indirect selection programs.

\section{REFERENCES}

Adams, J., E.D. Rothman, W.E. Kerr and Z.L. Paulino, 1977. Estimation of the number of sex alleles and queen matings from diploid male frequencies in a population of Apis mellifera. Genetics, 86: 583-596.

Alpatov, W.W., 1929. Biometrical studies on variation and races of the honey bee (Apis mellifera L.). Q. Rev. Biol., 4: 1-58.

Bulmer, M.G., 1985. The Mathematical Theory of Quantitative Genetics. Clarendon Press, Oxford.

Collins, A.M., 1986. Quantitative Genetics. In: Bee Genetics and Breeding, Rinderer, T.E. (Ed.). Academic Press, Orlando, pp: 283-304.

Edriss, M.A., M. Mostajeran and R. Ebadi, 2002. Correlation between honey yield and morphological traits of honeybee in isfahan.. J. Sci. Technol. Agric. Nat. Resour., 6: 91-103. 
Estoup, A., M. Solignac and J. Cornuet, 1994. Precise assessment of the number of patrilines and of genetic relatedness in honeybee colonies. Proc. R. Soc. London, 258: 1-7.

Falconer, D.S. and T.F.C. Mackay, 1996. Introduction to Quantitative Genetics 4th Edn., Longman, Harlow, UK., 978-0582243026, Pages: 464.

Goetze, G., 1940. Die Beste Biene. Liedloff, Loth Michalis, Leipzig.

Laidlaw, H.H. and R.E. Page, 1984. Polyandry in honey bees (Apis mellifera L.): Sperm utilization and intracolony genetic relationship. Genetics, 108: 985-997.

Milne, C.P., R.L. Hellmich and K.J. Pries, 1986. Corbicular size in workers from honeybee lines selected for high or low pollen hoarding. J. Apic. Res., 25: 50-52.

Moritz, R.A. and A. Klepsch, 1985. Estimating heritabilities of worker characters: A new approach using laying workers of the Cape honeybee (Apis mellifera capensis esch). Apidologie, 16: 47-56.

Mostajeran, M., M.A. Edriss and M.R. Basiri, 2006. Analysis of colony and morphological characters in honey bees (Apis mellifera meda). Pak. J. Biol. Sci., 9: 2685-2688.

Mostajeran, M., M.A. Edriss, R. Ebadi and G.H. Tahmasebi, 2002. Heritability estimates of morphological characters and honey yield of honeybee colonies in isfahan. J. Sci. Technol. Agric. Natur. Resour., 4: 126-126.
Oldroyd, B.P. and C. Moran, 1983. Heritability of worker characters in the honeybee (Apis mellifera). Aust. J. Biol. Sci., 36: 323-332.

Page, R.E. and R.A. Metcalf, 1982. Multiple mating, sperm utilization and social evolution. Am. Nat., 119: 263-281.

Poklukar, J. and N. Kezic, 1994. Estimation of heritability of some characteristics of hind legs and wings of honeybee workers (Apis mellifera carnica Polm.) using the half-sibs method. Apidologie, 25: 3-11.

Rinderer, T.E., 1977. Measuring the heritability of characters of honey bees. J. Apic. Res., 16: 95-98.

Ruttner, F., 1988. Biogeography and Taxonomy of Honeybees. Springer-Verlag, Berlin.

Ruttner, F., L. Tassencourt and J. Louveaux, 1978. Biometrical-statistical analysis of geographic variability of $A$. mellifera L. I. Material and methods. Apidologie, 9: 363-381.

SAS, 2000. SAS/STAT: Software Release. SAS Institute Inc., Cary, NC., USA.

Souza, D.C., C.D. Cruz, L.A.O. Campos and A.J. Regazzi, 2002. Correlation between honey production and some morphological traits in africanized honey bees (Apis melifera). Ciencia Rural, Santa Maria, 32: 869-872.

Szabo, T.I. and L.P. Lefkovitch, 1988. Fourth generation of closed population honey bee breeding 2 relationship between morphological and colony traits. Apidologie, 19: 259-274.

Winston, M.L., 1987. The Biology of the Honey Bee. Harward University Press, Cambridge, Pages: 209. 